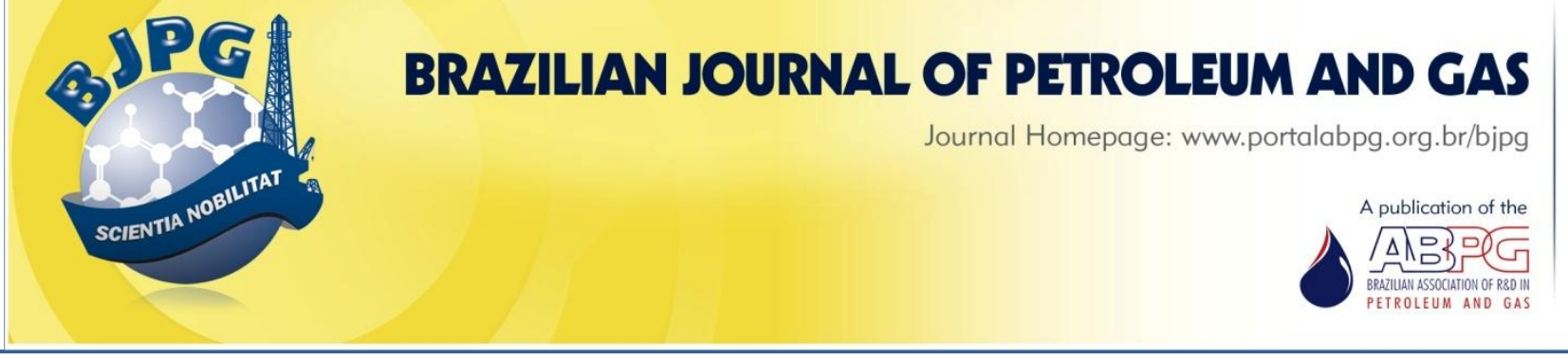

\title{
THE INFLUENCE OF IONIC LIQUID TYPE, CONCENTRATION, AND SLUG SIZE ON HEAVY OIL RECOVERY PERFORMANCE
}

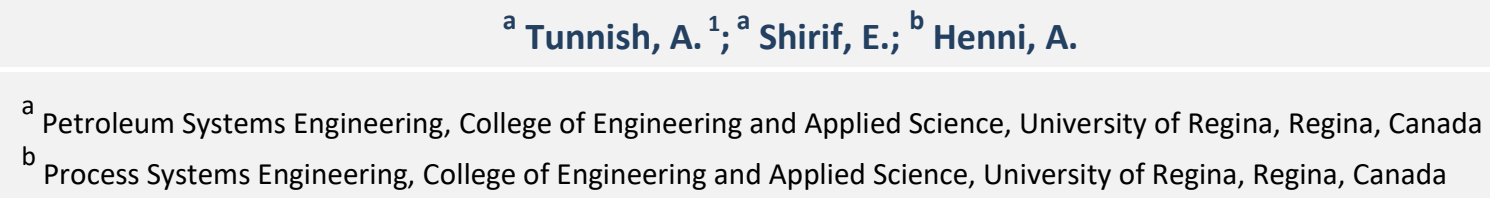

\begin{abstract}
Recent studies show that lonic Liquids (ILs) have the ability to improve oil recovery. In this experimental study, an imidazolium-based Room-Temperature Ionic Liquid (RTIL), 1-ethyl-3-methylimidazolium acetate ([EMIM][OAc]), was used to extract heavy oil $\left(14{ }^{\circ} \mathrm{API}\right)$ from unconsolidated packed sand samples. The RTIL was injected as slug, with different concentrations and sizes. The [EMIM][OAc] results were compared with the efficiency of 1-butyl-3-methylimidazolium bis(trifluoromethylsulfonyl)imide ([BMIM] $\left.\left[\mathrm{Tf}_{2} \mathrm{~N}\right]\right)$ and 1-dodecyl-3-methylimidazolium chloride ([DMIM] [CI]) ILs. The results indicate that the efficiency of IL depends mainly on the type of IL. A comparison with a well-known commercial surfactant (Sodium Dodecyl Sulfate, SDS) was performed, and the results confirmed the higher efficiency of the ionic liquids. Changes in Interfacial Tension (IFT), Surface Tension (SFT), and Zeta Potential (ZP) in the solution supported the recovery factor results. Finding the optimum concentration and slug size are significant factors in making the oil extraction process more economical.
\end{abstract}

\section{KEYWORDS}

[EMIM][OAc]; low saline water; enhanced oil recovery; cold heavy oil production; slug concentration; slug size

\footnotetext{
${ }^{1}$ To whom all correspondence should be addressed.

Address: Petroleum Systems Engineering, College of Engineering and Applied Science, University of Regina, Regina, Canada. Office: PTRC 212, 3737 Wascana Pkwy, Regina, SK S4S 0A2 Telephone: +306-351-5621 |e-mail: tunnisha@uregina.ca doi:10.5419/bjpg2017-0002
} 


\section{INTRODUCTION}

Various enhanced oil recovery (EOR) methods have been applied to increase the recovery factor (RF) of oil. It is, therefore, important to find other ways to extract oil from the interconnected pore spaces, either by increasing the viscosity of the extraction phase, decreasing the oil-sand adhesive forces, reducing the formation's water-oil interfacial tension (IFT), or reducing the oil viscosity in the porous medium. All these techniques have been successfully used, over the years, to improve oil mobility.

One of the proposed methods for improving oil mobility is the chemical flooding. Surfactants are compounds that have a hydrophilic head and a hydrophobic tail displaying an amphiphilic nature (Schramm, 2000). The importance of injecting surfactants (surface-active agents) in this process resides in their ability to reduce the IFT of the oilbrine-rock system in the reservoir (Dyke, 1997). They adsorb at the interface of the water-oil system, reducing the IFT, or at the liquid-rock interface, changing the rock's wettability (Lake, 1989) and improving the recovery factor (RF). In the last two years, new types of chemicals have been tested in laboratories for oil recovery. These chemicals are known as Room-Temperature Ionic Liquids (RTILs). Their outstanding properties allow them to tolerate the most severe reservoir conditions (high pressure and temperature) without degrading (Zhao et al., 2005). The application of RTILs in field EOR operations is promising (José-Alberto \& Jorge, 2011).

In a pioneering study, Painter et al. (2010) used three different types of imidazolium-based ILs to recover bitumen from tar sand. Their results showed that up to $90 \%$ of the bitumen could be extracted. In another study, IL was mixed with nheptane and acetone to remove bitumen from oil sand. The results were the recuperation of $95 \%$ of the bitumen from the oil sand sample (Li et al., 2011). Regarding core flooding experiments, imidazolium-based IL and brine mixtures were injected efficiently for tertiary recovery, recovering up to $13 \%$ of the original oil in place (OOIP) (Hezave et al., 2013a). When an Ammonium-based IL was mixed with brine, the injection of the mixture led to a $4.5 \%$ increase of the OOIP in tertiary recovery mode in RF (Bin-Dahbag et al., 2014).
This work studies, for the first time, the recovery of heavy oil using different ILs at room temperature. It also considers the effect of using slugs with various concentrations of ILs and the impact of slug size (SS). It quantifies the contribution of each recovery step on the recovery factor, observes the efficiency of different types of ILs, and the effects of salinity ratio on the effectiveness of IL. Changes in interfacial tension (IFT), surface tension (SFT), and zeta potential (ZP) were measured systematically and related to $\mathrm{RF}$ results.

\section{EXPERIMENTAL SECTION}

\subsection{Materials}

1-Ethyl-3-methylimidazolium acetate [EMIM][OAC] (> $95 \%$ mass), 1-butyl-3methylimidazolium bis(trifluoromethyl sulfonyl)imide [BMIM] [Tf $\left.{ }_{2} \mathrm{~N}\right]$ ( $\geq 99 \%$ mass), and 1dodecyl-3-methylimidazolium chloride [DMIM][Cl] ( $\geq 99 \%$ mass) were purchased from lonic Liquid Technologies (IOLITEC), and were used without purification. Their properties are presented in Table 1. Sodium dodecyl sulfate [SDS] ( $\geq 90 \%$ mass) was purchased from Sigma-Aldrich and used as a surfactant. The heavy oil sample was collected from the highly-aromatic Pelican Lake pool, and analyzed physically and chemically by Saskatchewan Research Council (SRC), as shown in Table 2. Its viscosity was measured at $22^{\circ} \mathrm{C}$. The oil sample was centrifuged at high speed to remove any fine solid particles and water before use. Finally, Ottawa sand was used to prepare the unconsolidated sand core samples.

\subsection{Methods and procedures}

All measurements were performed at room temperature, i.e., $(22 \pm 1){ }^{\circ} \mathrm{C}$. Brine was prepared by dissolving $1.00 \mathrm{~g}$ of sodium chloride $(\mathrm{NaCl})$ in 99 $\mathrm{mL}$ distilled water. Ionic liquid-brine mixtures were prepared by adding the required quantity of [EMIM][OAC] to brine, and both were placed in a stirrer (Cole-Parmer StableTemp Ceramic Stirring Hot Plate) for 20 to 30 minutes. A BrookField DV-II viscometer was used to measure the viscosities of Pelican oil and brine obtaining values of $(1200 \pm 2$ and $1.07 \pm 0.01) \mathrm{CP}$ at $(22 \pm 1)^{\circ} \mathrm{C}$, respectively. The densities of the aqueous solutions were measured 
Table 1. Properties of pure ionic liquids.

\begin{tabular}{|c|c|c|}
\hline Ionic Liquid & $\mu / \mathrm{cp}$ & $\rho /\left(\mathrm{g} / \mathrm{cm}^{3}\right)$ \\
\hline$[$ EMIM][OAc] & 136.6 & 1.101297 \\
\hline$[\mathrm{BMIM}]\left[\mathrm{Tf}_{2} \mathrm{~N}\right]$ & 51.3 & 1.438102 \\
\hline$[\mathrm{DMIM}][\mathrm{Cl}]^{*}$ & - & - \\
\hline
\end{tabular}

* The properties of the pure sample could not be measured due to its solid form at room temperature.

Table 2. Properties of Pelican oil.

\begin{tabular}{|c|c|c|}
\hline \multirow{2}{*}{$\rho /\left(\mathrm{g} / \mathrm{cm}^{3}\right)$} & $15^{\circ} \mathrm{C}$ & 0.971 \\
\cline { 2 - 3 } & $25^{\circ} \mathrm{C}$ & 0.964 \\
\hline \multirow{2}{*}{$\mu / \mathrm{cp}$} & $15^{\circ} \mathrm{C}$ & 2440 \\
\cline { 2 - 3 } & $22{ }^{\circ} \mathrm{C}$ & 1200 \\
\hline \multirow{2}{*}{$\begin{array}{c}\text { SARA, } \\
\text { wt. [\%] }\end{array}$} & Saturates & 26.3 \\
\cline { 2 - 3 } & Aromatics & 39.7 \\
\cline { 2 - 3 } & Resins & 14.4 \\
\hline
\end{tabular}

with an Anton Paar DSA $5000 \mathrm{M}$ instrument (manufacturer reported uncertainty is $1 \times 10^{-6}$ $\mathrm{g} / \mathrm{cm}^{3}$ ). Finally, a KRUSS K100 was used to measure the SFT of the displacing phases.

\subsection{Interfacial tension measurements}

A Rame-Hart Model 250 "standard contact angle Goniometer/Tensiometer with DROPimage Advanced Software" was used to measure the IFT of the aqueous solutions and Pelican oil at room temperature. The measurements of the IFT were based on the Young-Laplace equation ( $\mathrm{Xu}$ et al., 2013). The mixture-oil systems IFTs were measured by filling up the quartz cell with the mixture of brine and IL and forming an oil droplet at the tip of the needle ( 22 gauge). After allowing the droplet to reach stability, in about 40 minutes to 1 hour for brines and from 90 to 105 minutes for [EMIM][OAc] and brine mixtures, measurements were taken. Giving enough time for the oil droplet to stabilize is critical for measurement accuracy, depending on the type of oil sample (Kumar, 2012). Furthermore, the volume of the oil droplet is crucial for precise measurement, and should be in the range of 7 to $30 \mu \mathrm{L}$ (Buckley \& Fan, 2005). In this work, the droplet size of all measurements was $(13.5 \pm 0.3) \mu \mathrm{L}$. Only the final IFT point for each concentration was reported.

\subsection{Zeta potential measurements}

Zeta potential or the surface charge of the displacing mixtures was measured before injection of the core sample with a Zetasizer Nano-ZS instrument (Malvern). The mixtures were placed inside a folded capillary cell using a syringe or maintenance-free capillary cell that is primarily designed for ZP measurements. Air bubbles were removed by gentle tapping. The measurements were done three times, and the average value was reported.

\subsection{Core flooding experiments procedure}

The core flooding experiments were conducted in a standard core flooding system, as shown in Figure 1. It consisted of the following items: Syringe Pump (500 D Series), four transfer cylinders for Pelican oil, synthesized formation brine (1\% wt. $\mathrm{NaCl}$ ), incorporated formation brine + ILs mixtures, synthesized formation brine + SDS mixtures, digital pressure gauge (Heise Model), core holder, and test tubes. Flooding experiments were done at room temperature because the Pelican Lake heavy oil reservoir is shallow (less than $500 \mathrm{~m}$ ). First, a core holder with a length of $7.4 \mathrm{~cm}$ and an inside diameter of $3.3 \mathrm{~cm}$ was cleaned and dried. Following, one side of the sand back holder was closed by placing the cap and screen filter. Then, the unconsolidated sand ( $40-80$ mesh) was wet packed. After placing the screen filter and tightening the cap on the other side of the holder, the sand packs were dried. For each experiment, fresh Ottawa sands were used to make sure that similar wettability was present for all tests. Then, the samples were placed vertically with the outlet at the top, vacuumed, and saturated by the vacuum pump with distilled or deionized water (DW) to prevent air bubbles. After that, the porosity was determined. Then, the saturated samples were flooded with DW at different injection rates to determine the absolute permeability using Darcy Law. Finally, the samples were dried again, vacuumed, saturated with the synthetic brine ( $1 \% \mathrm{wt}$. $\mathrm{NaCl})$, and vertically connected to the core flooding system with the outlet at the bottom. After that, Pelican oil was continuously injected into the core sample at 1 


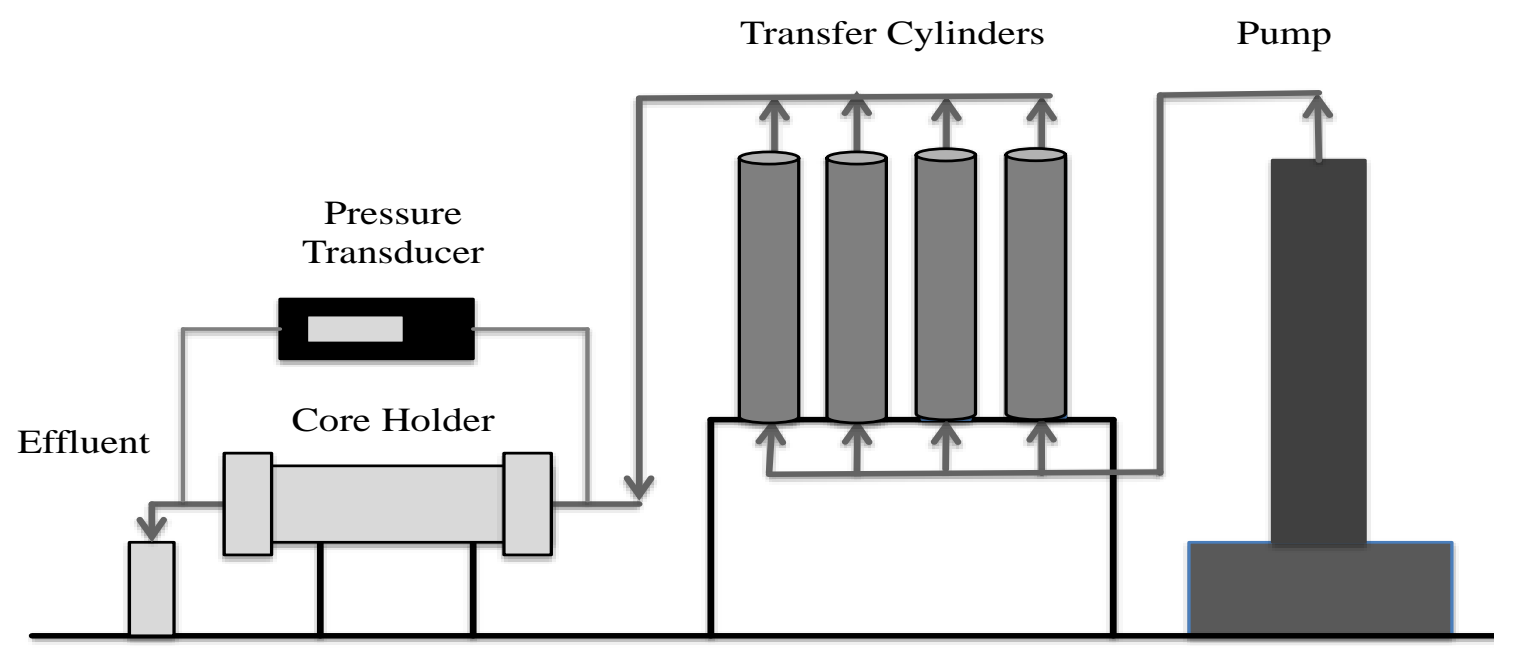

Figure 1. Schematic diagram of core flooding apparatus that consists of the syringe pump, transfer cylinders, digital pressure gauge, core holder, and test tubes.

$\mathrm{cm}^{3} / \mathrm{min}$ until water came out of the core outlet. The displaced aqueous solution represents the initial oil saturation $\left(\mathrm{S}_{\mathrm{oi}}\right)$ and the remaining water ratio in the core sample represents the irreducible water saturation $\left(S_{\text {wirr }}\right)$. The RF of the experiments was initiated using formation water ( $1 \% \mathrm{wt} . \mathrm{NaCl})$, where (3.34 \pm 0.05) Pore Volumes (PVs) of formation water were injected. This step was followed by the injection of different [EMIM][OAc] concentrations for the same slug size, for various slug sizes with constant concentrations, and different types of the studied RTILs. In the final step, the core sample was flushed with the same synthesized formation water ( $1 \%$ wt. $\mathrm{NaCl})$. All experiments were run at a constant displacement rate $\left(0.75 \mathrm{~cm}^{3} / \mathrm{min}\right)$ until less than $0.5 \%$ of the oil cut was produced. The samples were collected in test tubes and placed in the separator. The RF was calculated as the ratio of the sum of produced oil to the original oil in place.

\section{RESULTS AND DISCUSSIONS}

The effect of the brine that already existed in the porous medium as connate water, before injecting ILs/brine mixture, was neglected in our findings and interpretations.

\subsection{IFT behavior of displacing mixtures}

Studying the IFT of a brine-oil system is crucial for EOR. One could observe that the RF can be improved by decreasing the IFT (Al-Rossies et al., 2010). In this work, the reduction in IFT of brinePelican oil due to the addition of different concentrations of [EMIM][OAC] is presented in Figure 2. It is clear that all of the added concentrations of [EMIM][OAc] were able to decrease the IFT, which is needed to increase the $\mathrm{RF}$, although the reduction in the IFT was not to ultrahigh levels, as high as seen in some commercial surfactants. IFT reduction is not the only mechanism by which the IL acts to improve the recovery of oil, as will be discussed in the coming paragraphs.

Imidazolium-based ILs aggregate in aqueous solution, making them active on the surface (Modaressi et al., 2007). Imidazolium-based ILs display interface interaction and act as amphiphilic compounds, owning both hydrophilic and lipophilic properties when the alkyl chain length of the cation is longer than four carbon atoms (e.g. pentyl, hexyl, heptyl, octyl, etc.) (tuczak et al., 2008). It was observed that the acetate ion behaves as a surfactant and can reduce water-heptane IFT by gathering in the interface and imparting a negative charge (Lima et al., 2013). 


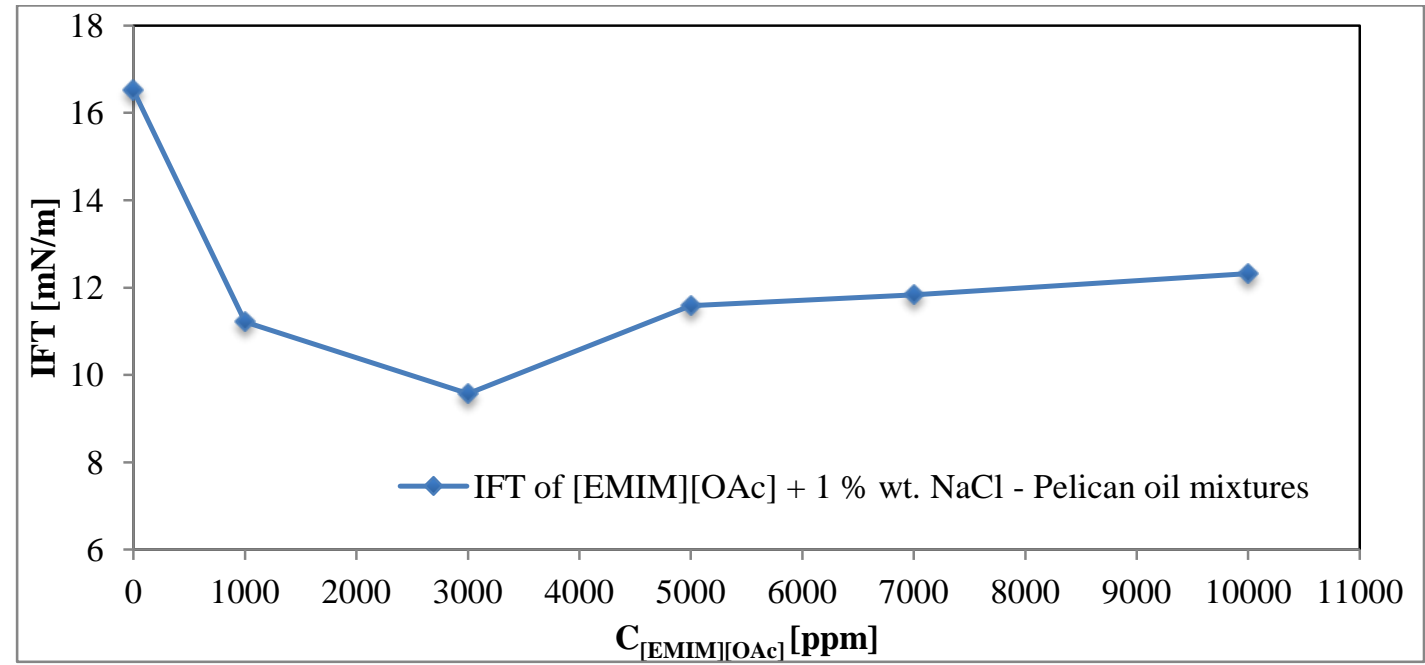

Figure 2. Variation of IFT for different concentrations of [EMIM][OAc] in brine-Pelican oil. 1,000, 3,000, 5,000, 7,000 , and $10,000 \mathrm{ppm}$ of these ILs were mixed with $1 \% \mathrm{wt}$. $\mathrm{NaCl}$ and placed in contact with Pelican oil to measure the IFT.

The presence of salt in aqueous solutions is significant for water-oil IFT reduction. It was observed in this study that the IFT of distilled water-Pelican oil system was $17.05 \mathrm{mN} / \mathrm{m}$, and reached $16.52 \mathrm{mN} / \mathrm{m}$ for the brine ( $1 \%$ wt. $\mathrm{NaCl}$ )Pelican oil system, which confirms the importance of including salts when lower IFT is desired. Previously, it had been proven that distilled wateroil IFT decreased when salt was added to the system (Isaacs et al., 1983). Water-oil IFT is not affected strongly by $\mathrm{NaCl}$, because the active interfacial substances are soluble in oil, and the interfacial activity of $\mathrm{NaCl}$ is, therefore, fragile (Bai et al., 2010). The surface charge of the cation in the interface was neutralized, and the decrease of the Debye screening length was obtained by increasing the salt ratio (Hezave et al., 2013b). Finally, the Critical Micelle Concentration (CMC) and the surface tension of long alkyl chain imidazoliumbased IL were found to decrease when sodium halide was added (Dong et al., 2008).

\subsection{SFT behavior of displacing mixtures}

SFT of aqueous solutions were measured to test the effect of various ratios of [EMIM] [OAc] on the SFT of synthesized saline water and, mainly, to determine the Critical Micelle Concentration (CMC) of this IL. The performance of the studied IL with $0.3,0.5$, and $1 \%$ wt. $\mathrm{NaCl}$ was, in general, quite similar. As shown in Figure 3, the addition of 100 $1,000 \mathrm{ppm}$ of [EMIM][OAc] drastically reduced the
SFT of all systems. Furthermore, a slight reduction was noticed when 1,000 to $4,000 \mathrm{ppm}$ of [EMIM][OAc] were added. However, the measurements of SFT became stable as the concentrations increased above $4,000 \mathrm{ppm}$. Two different regions (high and non-reduction zones) were found with the various slopes for different salinity ratios. The intersection of the lines of these two areas was considered to represent the CMC value. CMC was reached at $(1550 \pm 5),(1520 \pm 5)$, and $(1500 \pm 5)$ ppm for $0.3,0.5$, and $1 \%$ wt. $\mathrm{NaCl}$, respectively. Increasing the salinity decreased slightly the $\mathrm{CMC}$ values. This minor change in $\mathrm{CMC}$ values could be due to the type of aggregation of IL in brine. Wang et al. (2010) noticed a slight improvement in the aggregation number of imidazolium-based IL $\left(\left[\mathrm{C}_{10} \mathrm{mim}\right] \mathrm{Br}\right)$ as $\mathrm{NaCl}$ concentration increased (Wang et al., 2010).

\subsection{Effect of injecting 0.1 PV of [EMIM][OAc] on RF}

At this point, injecting (3.36 \pm 0.06$)$ PVs of synthesized formation water resulted in $(54.7 \pm 0.3$ $\%$ OOIP). After that, a 0.1 PV Slug Size (SS) with different concentrations (pure, 100,000, and 1,000 $\mathrm{ppm})$ of [EMIM][OAc] were injected to extract Pelican oil from the unconsolidated sand packs, followed by $(2.17 \pm 0.08)$ PVs of water flush (synthesized formation water). The average physical properties of the experiments are presented in Table 3. According to the additional 


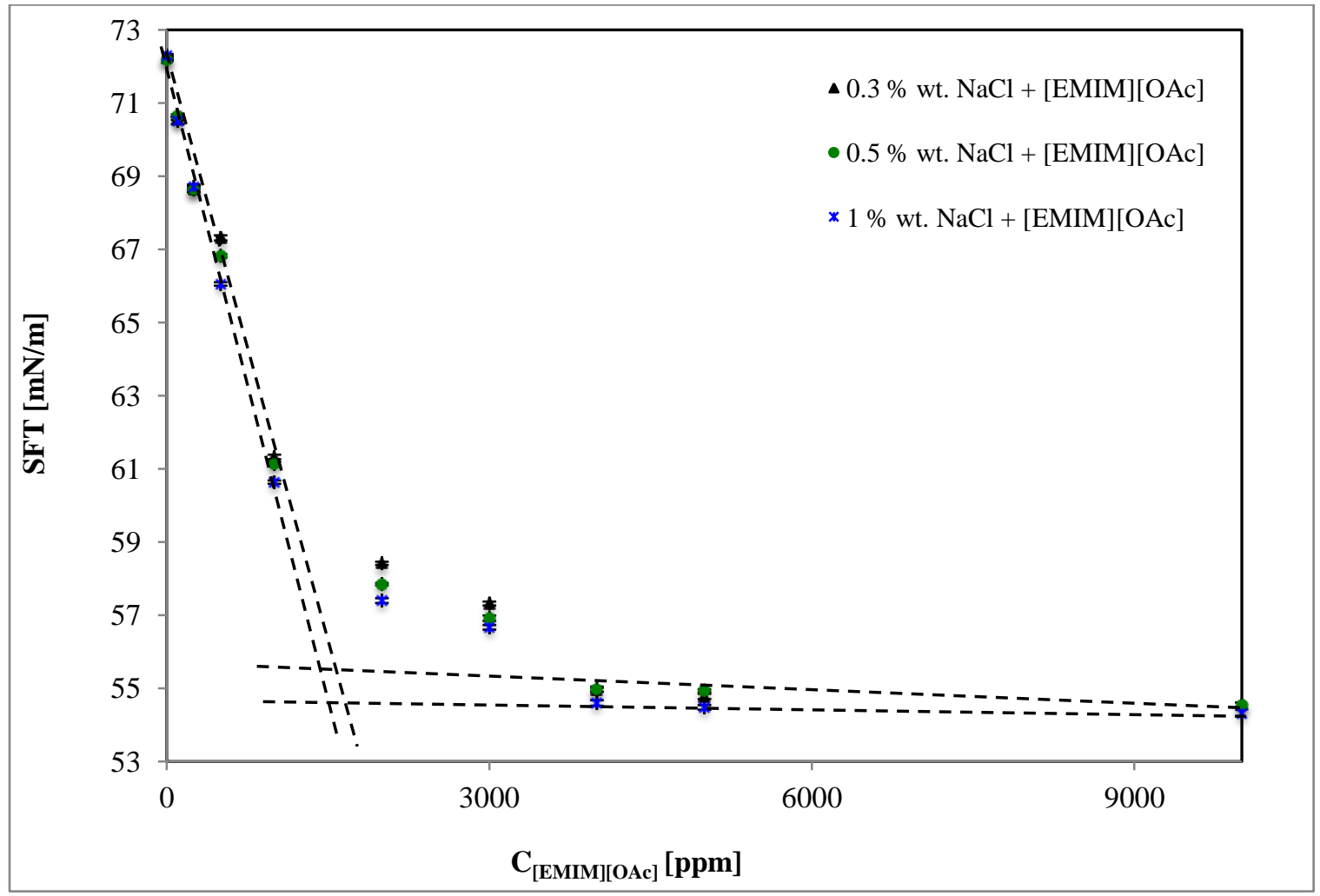

Figure 3. The effect of $\mathrm{NaCl}$ ratio on the SFT values of different [EMIM][OAc] concentrations.

RF results of the chemical slug and the water flush shown in Figure 4, the highest RF was obtained with pure [EMIM][OAc]. Then, it decreased to $100,000 \mathrm{ppm}$ and $1,000 \mathrm{ppm}$. Injecting the most effective concentration of ILS is important to the economics of the recovery operations. RFs of [EMIM][OAc]+brine mixtures were in this order: pure [EMIM][OAc] $(5.62 \%$ OOIP) $>100,000 \mathrm{ppm}$ $(5.00 \%$ OOIP $)=1,000$ ppm $(5.00 \%$ OOIP $)$. Then, injecting $1,000 \mathrm{ppm}$ of [EMIM][OAc] would be better than injecting $100,000 \mathrm{ppm}$ or $100 \%$ volume of [EMIM][OAc], economically speaking. Finally,

Table 3. Physical properties for various concentrations of [EMIM][OAc] in brine experiments.

\begin{tabular}{|c|c|}
\hline $\mathrm{PV} / \mathrm{cm}^{3}$ & $(22.7 \pm 0.2)$ \\
\hline Vo $/ \mathrm{cm}^{3}$ & $(20.3 \pm 0.2)$ \\
\hline $\mathrm{Ka} /$ Darcy & $(3.6 \pm 0.2)$ \\
\hline $\mathrm{S}_{\text {wirr }} / \%$ & $(10.3 \pm 0.9)$ \\
\hline$\Phi / \%$ & $(35.9 \pm 0.2)$ \\
\hline
\end{tabular}

injecting a pure IL slug and flushing the pore spaces with the designated formation water means that it is not necessary to mix IL with any other aqueous solution before introducing it to the porous medium in the actual reservoir.

\subsection{Effect of injecting different slug sizes of [EMIM][OAc] on RF}

In this phase, different slug sizes $(0.1,0.5$, and 1 $\mathrm{PV})$ of $1,000 \mathrm{ppm}$ of [EMIM][OAc], as the most economic concentrations, were injected. Initially, conventional water flooding $(3.3 \pm 0.1) \mathrm{PV}$ was done and resulted in 54.7 ( $\pm 0.5 \%$ OOIP). In the second stage, different slug sizes of $1,000 \mathrm{ppm}$ [EMIM][OAC] + $1 \%$ wt. $\mathrm{NaCl}$ mixtures were injected; and, finally, the samples were flushed with $2.13( \pm 0.2)$ PVs of synthesized formation brine. Figure 5 presents the obtained RF values. Results of the chemical slugs and the flush water show that the highest RF was found when $1 \mathrm{PV}$ (6.67\% OOIP) of the tested ILs was injected, which was slightly better than that of 0.5 PV $(6.54 \%$ OOIP). The smallest RF, however, was found with the $0.1 \mathrm{PV}$ slug size injected (5.00\% OOIP). Accordingly, 0.5 PV would economically be 


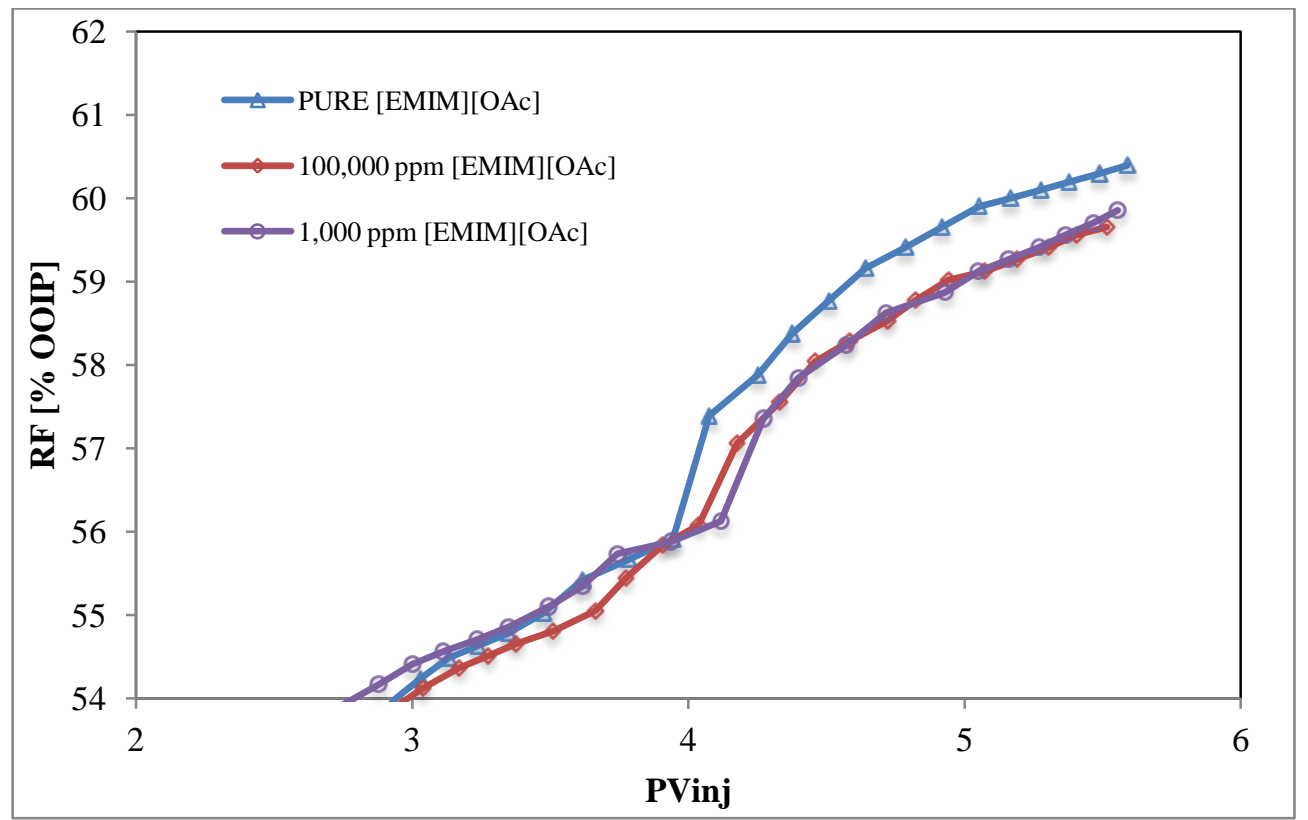

Figure 4. Additional RF after adding different concentrations of [EMIM][OAc] to brine [0.1 PV].

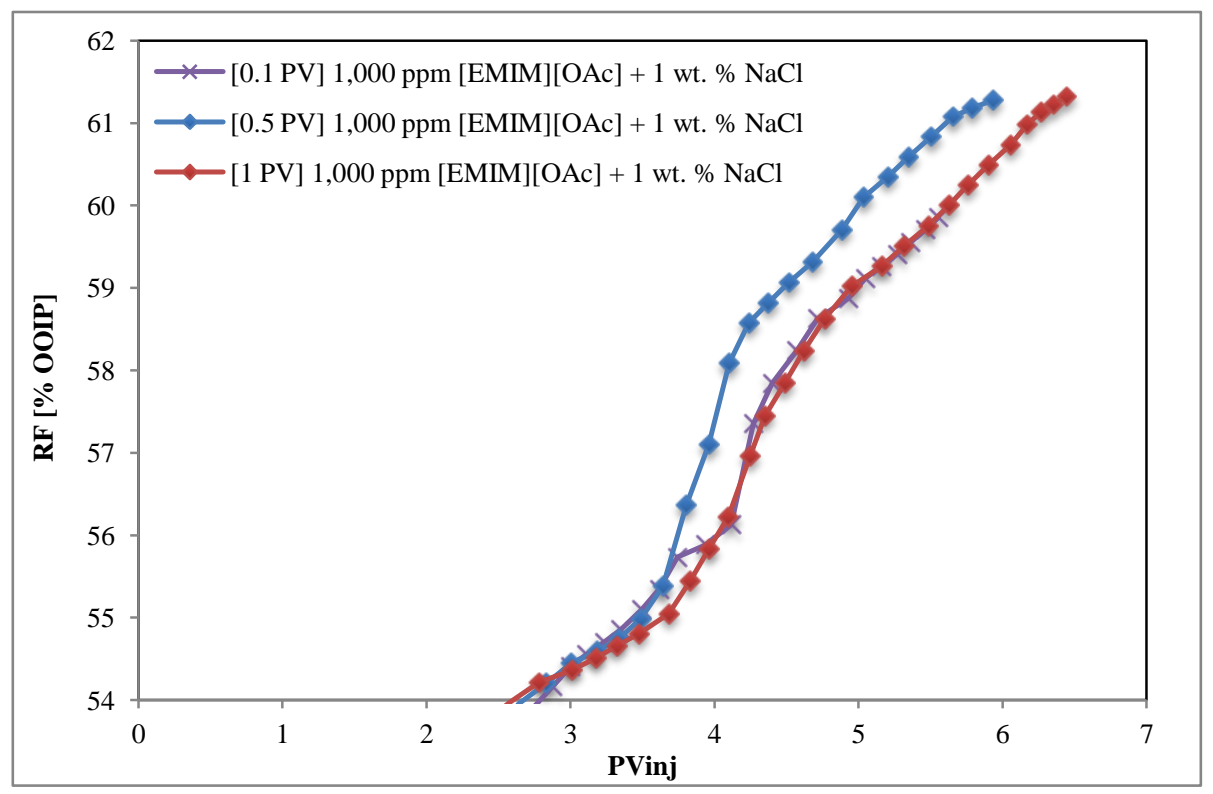

Figure 5. Additional RF after injecting different slug sizes of 1,000 ppm [EMIM][OAc] + brine mixtures.

considered the optimum SS for [EMIM] [OAC]. There is a distinct advantage in injecting ILs as even a very minute SS and low concentrations of IL would give a noticeable rise in RF. In a recent study, it was also found that increasing the SS beyond the optimum size led to just minor improvements (Dong et al., 2009), as observed when the SS increased from 0.5 $\mathrm{PV}$ to $1 \mathrm{PV}$. Although [EMIM][OAc] is not efficient to reduce the IFT of the studied system, it is active in improving heavy oil RF. Bin-Dahbag et al. (2014) found that the injection of ammonium-based IL was able to enhance the RF up to $4.5 \%$ OOIP, despite the fact that it was not efficient in reducing the IFT of brine-medium Saudi crude oil to ultralow values (Bin-Dahbag et al., 2014). In another study, two Deep Eutectic Solvents (DESs), which are equivalent to ionic liquids, were found to increase the IFT of the system from $23.5 \mathrm{mN} / \mathrm{m}$ to 27.1 $\mathrm{mN} / \mathrm{m}$ and $26.0 \mathrm{mN} / \mathrm{m}$ by adding $5 \%$ wt. DES1 and DES2, respectively. DES1 and DES2 were able to 
Table 4. Zeta potential of the injected and displaced various concentrations of [EMIM][OAc] + brine mixtures in the displaced mixtures versus RF.

\begin{tabular}{|c|c|c|c|}
\hline $\mathrm{ClL}_{\mathrm{LL}} / \mathrm{ppm}$ & $\begin{array}{c}\mathrm{ZP} / \mathrm{mV} \\
\text { (Before run) }\end{array}$ & $\begin{array}{c}\mathrm{ZP} / \mathrm{mV} \\
\text { (After run) }\end{array}$ & $\begin{array}{c}\mathrm{RF} \text { Incremental } \\
{[\% \mathrm{OIP}]}\end{array}$ \\
\hline PURE (100\%) [EMIM][OAc] & $(-1.32 \pm 0.01)$ & $(-2.78 \pm 0.01)$ & 5.62 \\
\hline $100,000[\mathrm{EMIM}][\mathrm{OAc}]$ & $(-2.20 \pm 0.01)$ & $(-4.67 \pm 0.03)$ & 5.00 \\
\hline $1,000[\mathrm{EMIM}][\mathrm{OAc}]$ & $(-2.38 \pm 0.04)$ & $(+1.46 \pm 0.01)$ & 5.00 \\
\hline
\end{tabular}

Table 5. Zeta potential of the injected and displaced various slug sizes of [EMIM][OAc]+brine mixtures in the displaced mixtures versus RF.

\begin{tabular}{|c|c|c|c|}
\hline $\mathrm{SS} / \mathrm{cm}^{3}$ & $\begin{array}{c}\mathrm{ZP} / \mathrm{mV} \\
\text { (Before run)* }\end{array}$ & $\begin{array}{c}\mathrm{ZP} / \mathrm{mV} \\
\text { (After run) }\end{array}$ & $\begin{array}{c}\mathrm{RF}_{\text {Incremental }} \\
{[\% O O I P]}\end{array}$ \\
\hline $0.1[\mathrm{EMIM}][\mathrm{OAc}]$ & $(-2.38 \pm 0.04)$ & $(+1.46 \pm 0.02)$ & 5.00 \\
\hline $0.5[\mathrm{EMIM}][\mathrm{OAc}]$ & $(-2.38 \pm 0.04)$ & $(-18.41 \pm 0.04)$ & 6.54 \\
\hline $1.0[\mathrm{EMIM}][\mathrm{OAc}]$ & $(-2.38 \pm 0.04)$ & $(-15.90 \pm 0.01)$ & 6.67 \\
\hline
\end{tabular}

* The same sample was injected with different slug sizes.

improve the RF up to $6.3 \%$ and $8.7 \%$ [OOIP] of heavy oil, respectively (Mohsenzadeh et al., 2015a). One of the proposed mechanisms that provide an improvement in the RF by DESs solution is the viscous force. At the same condition, the viscosity of DES solution was greater than that of brine, which might be the reason for additional oil recovery by DES solution compared to brine (Mohsenzadeh et al., 2015b). In our study, the viscosity of pure [EMIM][OAc] is (136.6 \pm 0.4$) \mathrm{cP}$, which would lead undoubtedly to an effective increase in the viscosity of the displacing phase and might be one of the reasons for improving the RF. Furthermore, it has been observed that injecting DES causes wettability alteration that might be the primary mechanism of the improvement in oil recovery (Mohsenzadeh et al., 2015b). Moreover, the effect of [EMIM][OAc] on recovery of oil was similar to the previous studies. It may affect the wettability of the sand surface resulting in a noticeable enhancement in RF.

\subsection{Zeta potential (ZP) behavior of displacing mixtures}

As shown in Table 4, displacing solutions with greater ZP values resulted in higher RF. All IL-brine mixtures have $Z P$ values greater than that of the synthesized brine itself $(-12.9 \pm 0.2 \mathrm{mV})$. Therefore, all [EMIM][OAc]-brine mixtures, at any concentrations, have the ability to extract more oil than brine alone. ZP values were measured also for the displaced phases, and the same trend remained: the higher the $\mathrm{ZP}$, the better was the RF. Thakkar et al. (2015) observed similar trends in ZP measurements when different concentrations of alkyl triphenylphosphonium bromide [CnTPPBr] were added to a mixture of distilled water and a nonionic surfactant, Triton X-100. The increase in $Z P$ value for the mixture observed might be due to the increase in the ionic character of the solution with the addition of the ionic liquid.

In different SS results, all injected mixtures of the studied IL and synthesized brine mixtures had the same ZP, as shown in Table 5. They ended up, however, with different RFs. The ZP of the displaced phases at the outlet of the sand pack holder had different values. The ZP values of the displaced samples that were smaller resulted in higher RF in mixtures of both IL and brine, as presented in Table 5.

Based on the ZP measurements in different phases, as shown in Table 6, the presence of IL has a strong influence in changing the ZP value of any system. For the brine-Pelican oil system, the added 
Table 6. Zeta potential of different systems of brine/Pelican oil/[EMIM][OAc]/sand.

\begin{tabular}{|l|c|}
\hline \multicolumn{1}{|c|}{ Phase } & $\mathrm{ZP} / \mathrm{mV}$ \\
\hline Brine $[1 \%$ wt. NaCl$]$ & $(-12.9 \pm \pm 0.2)$ \\
\hline Brine $[1 \%$ wt. $\mathrm{NaCl}]+$ Pelican Oil & $(-28.9 \pm \pm 0.2)$ \\
\hline Brine $[1 \%$ wt. $\mathrm{NaCl}]+$ Pelican Oil + 1,000 ppm [EMIM][OAc] & $(-16.3 \pm 0.2)$ \\
\hline Brine [1\% wt. NaCl] + Sand & $(-3.4 \pm 0.1)$ \\
\hline Brine [1\% wt. NaCl] + Pelican Oil + Sand & $(-5.2 \pm \pm 0.2)$ \\
\hline Brine [1\% wt. NaCl] + Pelican Oil + 1,000 ppm [EMIM][OAc] +Sand & $(+1.9 \pm 0.1)$ \\
\hline
\end{tabular}

concentration of the examined IL was efficient in increasing the value of the ZP. In addition, the efficiency of this IL on improving the ZP values was noticeable in the case of the brine-oil-sand system. Then, these ILs "neutralize" the charge of the examined system, which could end up with wettability alteration.

\subsection{Effect of IL type on the incremental RF}

Investigating the efficiency of different types of ILs is significant for EOR. After conventional waterflooding, $1 \mathrm{PV}$ of IL ([DMIM][Cl] or $\left.[\mathrm{BMIM}]\left[\mathrm{Tf}_{2} \mathrm{~N}\right]\right)+1 \% \mathrm{wt}$. $\mathrm{NaCl}$ mixture was injected, followed by injecting ( $2.1 \pm 0.1)$ PV of synthesized formation brine $(1 \% \mathrm{wt}$. $\mathrm{NaCl})$ to flush the sand pack samples in the final step. The results of these runs, as presented in Figure 6, show that the additional RF depends on the IL type. In comparison with [EMIM][OAc], the incremental RF of the chemical slug and extended waterflooding decreases in the following order: [DMIM][Cl] $(8.18$ $\%$ OOIP $)<$ [EMIM][OAC] $(6.67 \%$ OOIP $)<$ [BMIM] $\left[\mathrm{Tf}_{2} \mathrm{~N}\right](4.64 \%$ OOIP). It is clear that all of the ILs have different efficiencies. One of the factors that may influence the performance of the displacing phases is the ZP value (surface alteration). The zeta potential values for

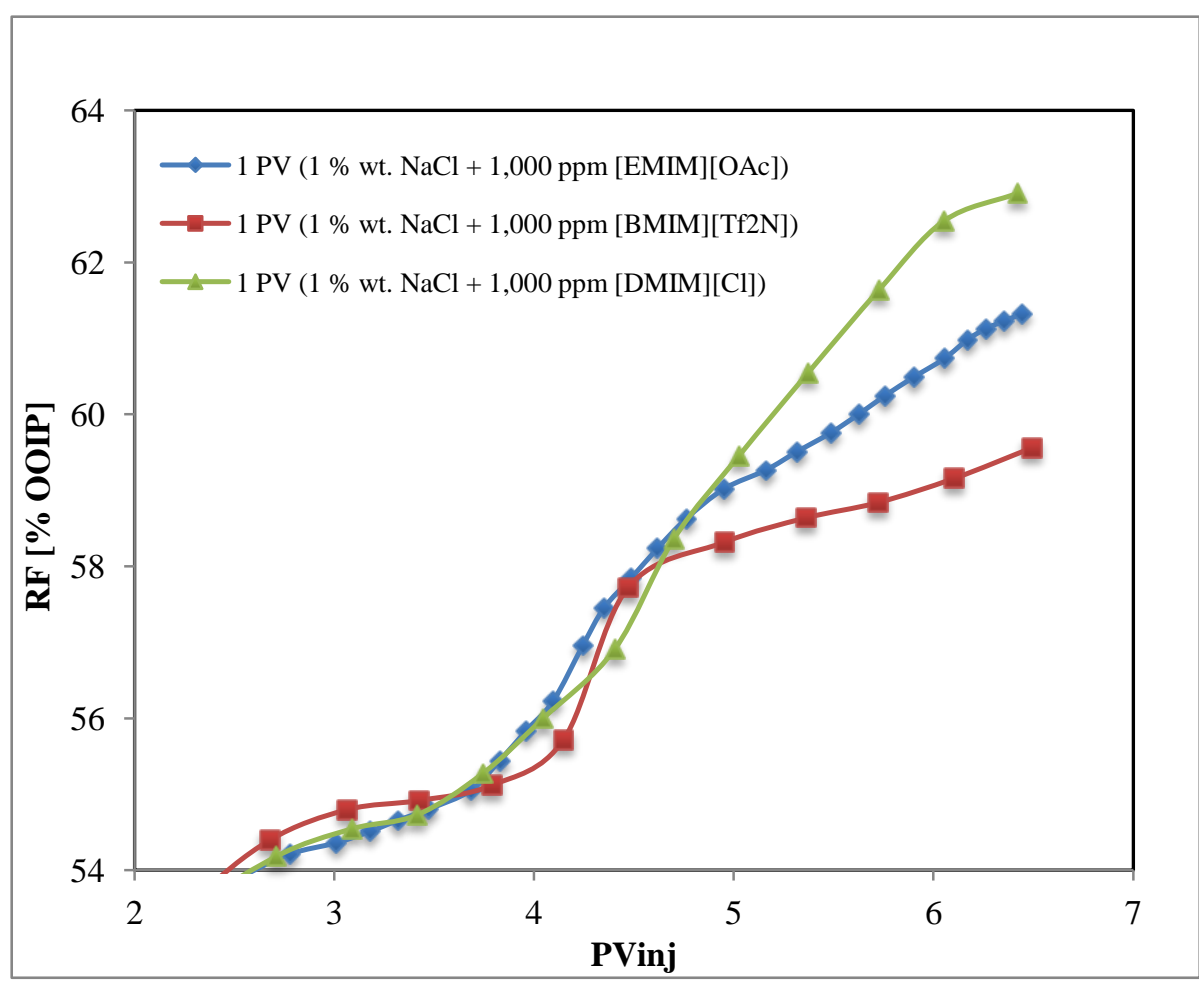

Figure 6. Effect of IL type on the additional RF. 


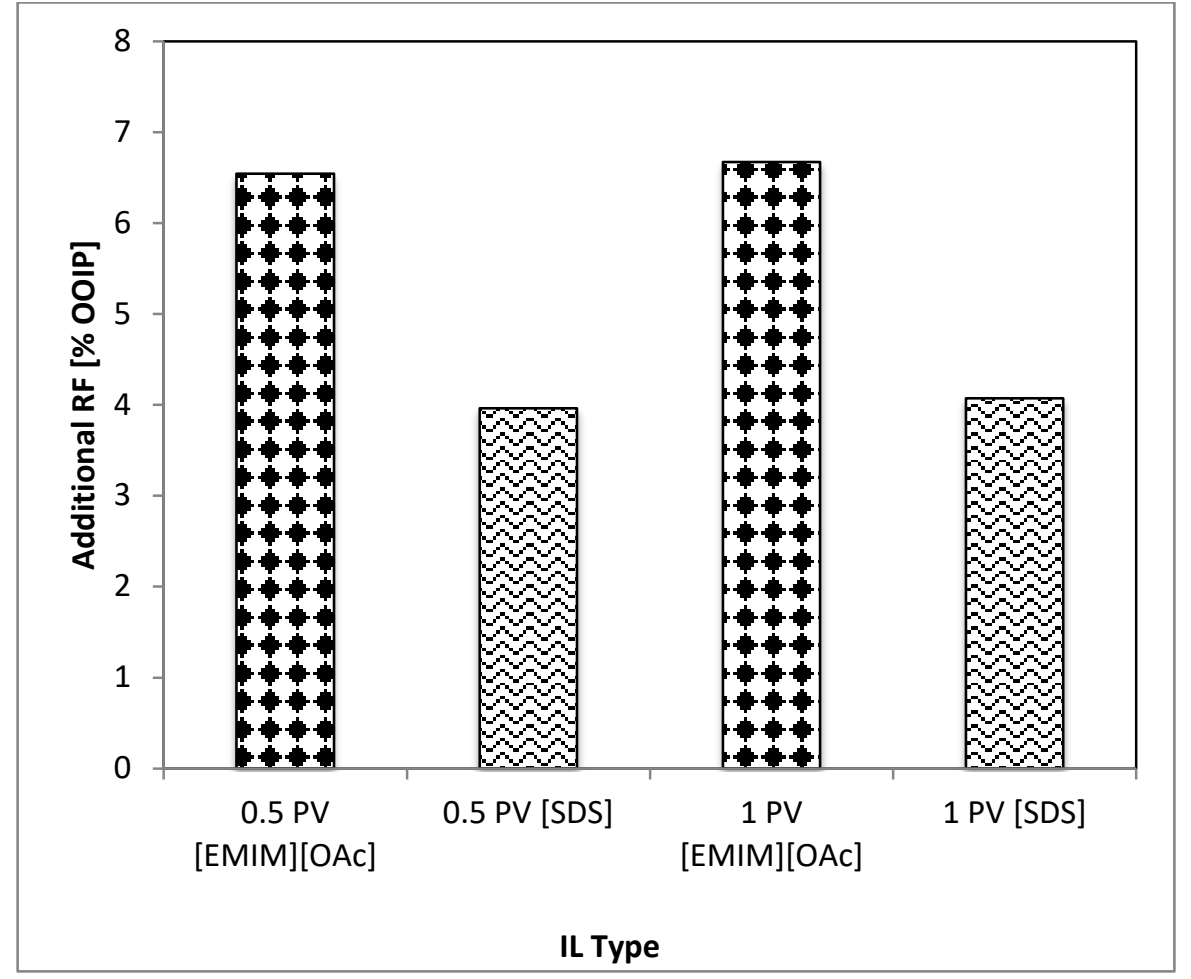

Figure 7. Incremental RF of injecting different slug sizes of ILs $+1 \%$ wt. $\mathrm{NaCl}$ and SDS $+1 \% w t . \mathrm{NaCl} .0 .5$ and $1 \mathrm{PV}$ slugs of the chemicals $+1 \%$ wt. $\mathrm{NaCl}$ mixtures were injected to study the effect of the slug sized and chemical concentration.

[DMIM][Cl], [EMIM][OAC], and [BMIM] $\left[\mathrm{Tf}_{2} \mathrm{~N}\right]+1$ wt. \% NaCl were $(28.5 \pm 0.3) \mathrm{mV},(-2.38 \pm 0.04)$ $\mathrm{mV}$, and $(-5.3 \pm 0.1) \mathrm{mV}$, respectively. The efficiency of the displacing mixtures on improving the RF was enhanced when the zeta potential value increased. Besides, the effect of the changes in viscosity of the injected mixtures was investigated. According to type of IL, it was found the viscosity to increase in this order: [BMIM] $\left[\mathrm{Tf}_{2} \mathrm{~N}\right](1.15 \pm 0.02$ $\mathrm{CP})<$ [EMIM][OAc] $(1.19 \pm 0.02 \mathrm{cP})<$ [DMIM] [CI] $(1.25 \pm 0.04 \mathrm{cP})$, which totally agrees with the improvement in the additional RF.

\subsection{Comparison between the effects of commercial surfactant and ionic liquid on RF}

In this step, 1,000 ppm of SDS surfactant was mixed with $1 \%$ wt. $\mathrm{NaCl}$ and injected as slugs with different sizes to compare their effectiveness in enhancing RF with that of [EMIM][OAc]. The injection of the [SDS] mixtures was under the same conditions that applied on the slugs of the studied IL. In other words, 0.5 and 1 PV of the mixture were injected, and their RFs were 3.96 and 4.07 [\%
OOIP], respectively. In comparison, [EMIM][OAc] were more efficient than [SDS], as shown in Figure 7. Pereira et al. (2014) obtained similar results while studying the efficiency of commercial surfactants and IL on decreasing the IFT of brinemedium crude oil (API 27.6 and $50.9 \mathrm{cP}$ ). They found that a commercial surfactant [Petrostep] apparently reduced the IFT of the system from 19.1 to $4.3 \mathrm{mN} / \mathrm{m}$, while IL (1-ethyl-3methylimidazolium tosylate $\left[\mathrm{C}_{2} \mathrm{mim}\right.$ ][OTs]) slightly decreased the IFT from 19.1 to only $17.0 \mathrm{mN} / \mathrm{m}$. However, the additional RFs obtained from injecting the commercial surfactant ([Petrostep]) and IL ([C $\left.\left.\mathrm{C}_{2} \mathrm{mim}\right][\mathrm{OTs}]\right)$ were 33.3 and $65.7 \% \mathrm{wt}$., respectively (Pereira et al., 2014). Although the SDS surfactant is more efficient to reduce the SFT of the displacing mixture and had lower CMC (150 $\pm 10 \mathrm{ppm}$ ) than the ILs at the same $\mathrm{NaCl}$ ratio, as shown in Figure 8, it is less efficient to improve the RF. One of the factors that may affect the performance of the displacing phase is the ZP value. These experiments show that the efficiency of the displacing mixture on improving the RF increased as the ZP increased. The ZP value of [SDS] $+1 \%$ wt. $\mathrm{NaCl}$ was $(-24 \pm 1) \mathrm{mV}$, which was much 


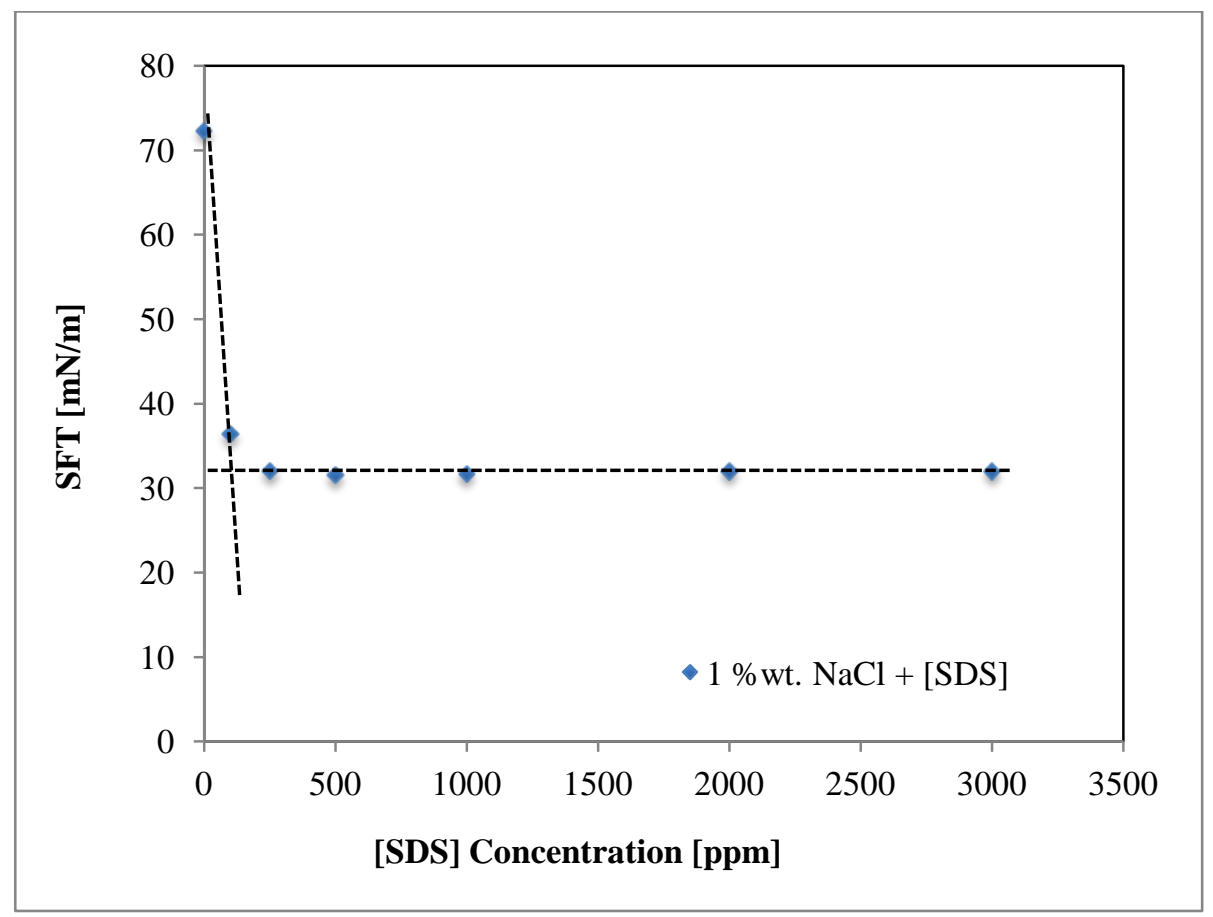

Figure 8. SFT variations for various concentrations of [SDS] and $1 \% \mathrm{wt}$. $\mathrm{NaCl}$ solutions. 100, 250, 500, 1,000, $2,000,3,000, \mathrm{ppm}$ of [SDS] were mixed with $1 \% \mathrm{wt}$. $\mathrm{NaCl}$ to measure the SFT.

lower than the ZP value of [EMIM][OAc] [(- $2.38 \pm$ 0.04) $\mathrm{mV}$. In addition, the influence of aromatic interaction between the aromatic ring of the IL and aromatic compounds of oil sample is considered as the second mechanism to improve the RF in the case of IL flooding. Cao et al. (2014) found that due to the powerful attraction with aromatic rings through $\pi-\pi$ interactions, resulting from the presence of imidazolium head group, the elasticity of b-casein/[Cnmim] $[\mathrm{Br}]$ system is greater than that of the conventional surfactant, showing that the adsorption layer created by b-casein/[Cnmim] $[\mathrm{Br}]$ is remarkably stronger (Cao et al., 2014).

\subsection{Effect of the salinity ratio on the efficiency of IL}

1 PV of low salinity water (LSW) and 1,000 ppm [EMIM][OAc] mixtures were introduced to the porous medium as a slug. Experimentally, two concentrations of $\mathrm{NaCl}$ ( 0.3 and $0.5 \%$ wt.) were added to the distilled water to prepare water samples with lower salinity than the synthesized formation water. These LSWs were mixed separately with $1,000 \mathrm{ppm}$ of [EMIM][OAc]. As presented in Figure 9, the incremental RF of the IL + saline water mixtures and the $(2.05 \pm 0.7)$ PVs synthesized formation water increase as the salinity of the displacing mixture decreases. Depending on the displacing phase salinity, the incremental RFs of $0.3,0.5$, and $1 \%$ wt. $\mathrm{NaCl}$ are 7.12, 6.72, and 6.67 (\% OOIP), respectively. This finding proves the efficiency of [EMIM][OAC] in improving heavy oil recovery, especially with the combination with LSW. One of the possible mechanisms of LSW efficiency is wettability alteration. Shaddel et al. (2014) observed that the rock wettability was altered to more water-wet when LSW was injected, which resulted in higher RF. The other factor is the ZP of the displacing phases. It was found that the ZP values of 1,000 ppm of [EMIM] [OAC] $+0.3,0.5$, and $1 \% \mathrm{wt}$. NaCl are $(-1.05 \pm 0.01) \mathrm{mV},(-1.24 \pm 0.02) \mathrm{mV}$, and $(-$ $2.38 \pm 0.04) \mathrm{mV}$, respectively. Besides, the influence of the salinity variation on the effectiveness of $1,000 \mathrm{ppm}$ [EMIM][OAc] to reduce the IFT of the brine-Pelican oil was considered. It was found that the IFT of $1,000 \mathrm{ppm}$ of [EMIM] [OAC] $+0.3,0.5$, and $1 \%$ wt. $\mathrm{NaCl}$ are $(7.61$ $\pm 0.01),(9.91 \pm 0.01)$, and $(11.21 \pm 0.01) \mathrm{mN} / \mathrm{m}$, respectively. Then, both ZP and IFT values of the injected mixtures support the enhancements of additional RF. 


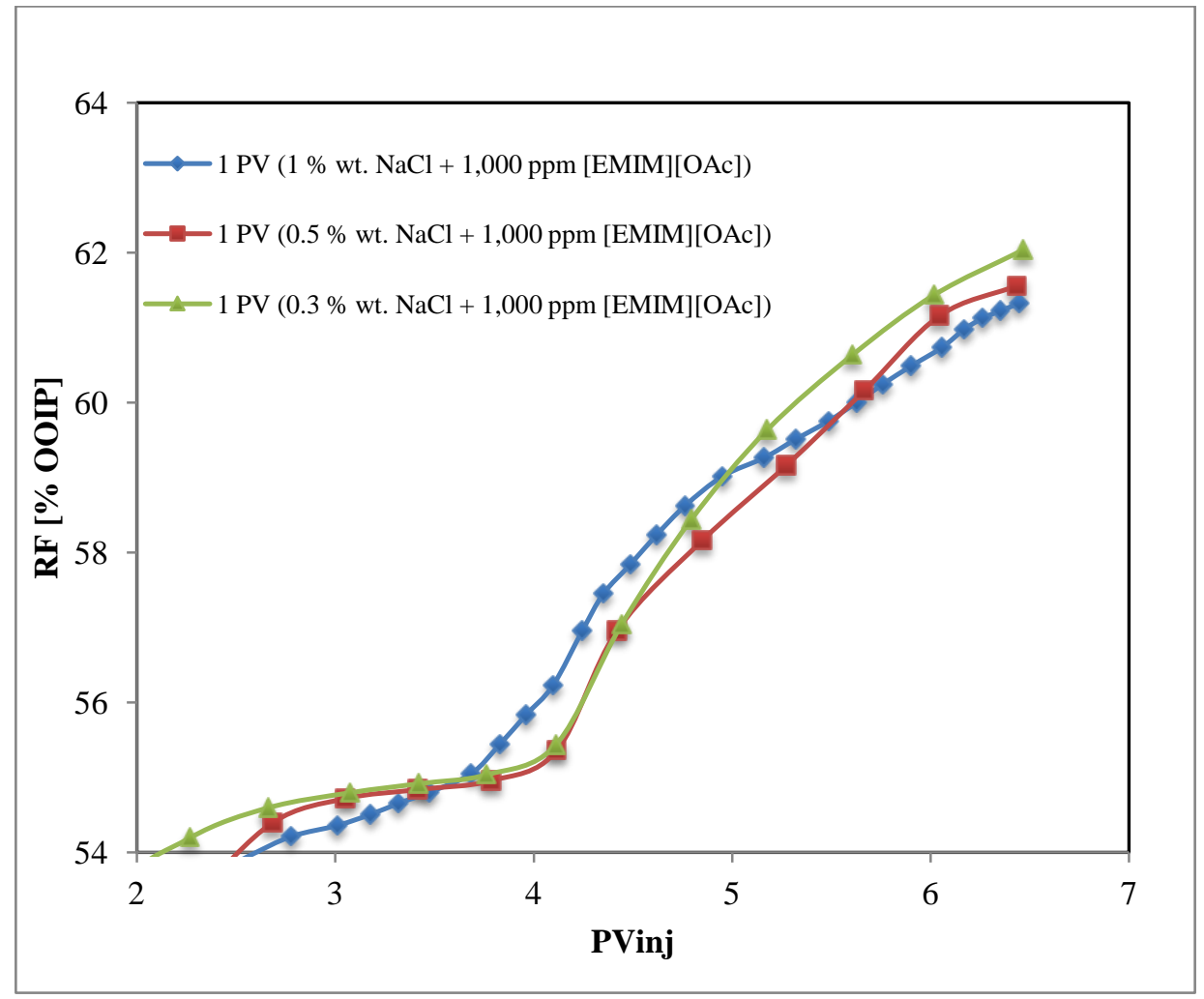

Figure 9. The effect of salinity on the efficiency of [EMIM][OAc].

Overall, the increase in RF could be explained partially by the decrease in IFT (Figure 2) and SFT (Figure 3), and the high viscosity of the ILs (Table 1). Also, the driving force for the aromatic separation of oil by the IL is the $\pi-\pi$ interaction between the large aromatic fraction of the Pelican heavy oil (39 wt. \%), and the aromatic cations of the ionic liquid ([EMIM][OAc]) could also be a contributing factor. The increase in RF can also be explained by the interaction of the negative charge on the surface of the sand (weak acid) and the very basic ionic liquid [EMIM][OAc] $(\mathrm{pH}=14.2)$ (Ober \& Gupta, 2012). Therefore, more studies are required in order to explain the molecular mechanism for the interaction between different ILs and oil types. It is also important to investigate the effect of the presence of IL on the rock wettability, and the impact of the rock type on the efficiency of the ionic liquids.

\section{CONCLUSIONS}

Injecting ILs into porous medium for EOR operations affected successfully heavy oil recovery.
This research demonstrates the efficiency of imidazolium-based RTIL in reducing SFT/IFT, changing the ZP and improving RF of the Pelican oil at room condition. Various amounts of [EMIM][OAc] were mixed with brine and injected in the porous medium as slugs to recover heavy oil from Ottawa sand at room conditions. Increases in $\mathrm{RF}$ were related to the ZP and IFT of the displacing fluids, in that higher ZP and lower IFT values of the extraction phases resulted in better recovery factors. Although $0.5 \mathrm{PV}$ of either [EMIM] [OAc] +1 $\%$ wt. $\mathrm{NaCl}$ was considered as the optimum SS, the lowest SS (0.1 PV) ended up with significant improvement in RF. Besides, injecting $0.1 \mathrm{PV}$ mixture of $1,000 \mathrm{ppm}$ of [EMIM][OAc] $+1 \% \mathrm{wt}$. $\mathrm{NaCl}$ resulted in similar RF to that of 100,000 of [EMIM] $[A c]+1 \%$ wt. NaCl. Hence, a higher ratio of IL does not always enhance noticeably the RF. In comparison, the efficiency of [EMIM][OAC] in enhancing the RF was better than [BMIM] $\left[\mathrm{Tf}_{2} \mathrm{~N}\right]$ and less efficient than [DMIM][Cl]. At the same conditions, SS and concentration, [EMIM] [OAC] was better than a commercial surfactant, [SDS], in improving the recovery factor of heavy oil.

It is important to note that the high reduction in 
IFT represents an improvement in RF. Therefore, the additional RF is not only due to IFT decrease but also to changes in $\mathrm{ZP}$, the essential characteristics ([EMIN][OAc]) that lead to an interaction with the weak acid character of the sand, an increase in the viscosity of the solution, the presence of aromaticity in the IL, and perhaps to other unknown mechanisms.

One could also observe that injecting the pure quantity of IL as slug efficiently means that IL does not need to be pre-mixed with any other aqueous solution for injection in actual reservoirs.

In summary, the highlight of this study is that the investigated IL has not been previously tested for flooding experiments extracting heavy oil at room conditions. The experiments were done with unconsolidated sands (not in batch mode) to mimic field operations. The experimental results obtained can be considered as part of an underlying database of cold heavy oil production techniques by injecting IL in different slug sizes, at various concentrations, and combined with LSW. Finally, the RF results for the ILs were compared with those obtained for a commercial surfactant (SDS) for the first time.

\section{ACKNOWLEDGEMENTS}

The authors would like to acknowledge the contribution of the Petroleum Technology Research Center (PTRC) and Western Diversification (WD) for providing grants to establish and operate a state-of-the-art Produced Water Treatment Laboratory (PWTL) at the University of Regina.

\section{NOMENCLATURE}

$\mathrm{C}_{\text {[EMIM][OAc]: }}$ [EMIM][OAc] concentration;

ka: absolute permeability;

OOIP: originally oil in place;

ppm: part per million;

$\mathrm{PV}$ : pore volume;

$P V_{\text {inj: }}$ injected pore volume;

PVs: pore volumes;

$\mathrm{RF}_{\text {Incremental: }}$ extra or additional recovery factor;

$\mathrm{RF}_{\mathrm{T}}$ : total recovery factor;
RTIL: room temperature ionic liquid;

RTILs: room temperature ionic liquids;

SARA: saturates, aromatics, resins and asphaltenes;

$\mathrm{V}_{\mathrm{o}}$ : oil volume;

$\rho$ : density

$\mu$ : viscosity

$\Phi:$ porosity.

\section{REFERENCES}

Al-Rossies, A. A. S.; Al-Anazi, B. D.; Paiaman, A. $M$. Effect of $\mathrm{pH}$-values on the contact angle and interfacial tension. NAFTA, v.61(4), p. 181-186, 2010. http://hrcak.srce.hr/52263

Bai, J.; Fan, W.; Nan, G.; Li, S.; Yu, B. Influence of Interaction Between Heavy Oil Components and Petroleum Sulfonate on the Oil-Water Interfacial Tension. Journal of Dispersion Science and Technology, v.31(4), p. 551-556, 2010. https://doi.org/10.1080/01932690903167475

Bin-Dahbag, M. S.; Al-Quraishi, A. A.; Benzagouta, M. S.; Kinawy, M. M.; Al-Nashef, I. M.; Al-Mushaegeh, E. Experimental Study of Use of Ionic Liquids in Enhanced Oil Recovery. Journal of Petroleum and Environmental Biotechnology, v.4(6), 2014.

Buckley, J. S.; Fan, T. Crude Oil/Brine Interfacial Tensions. In: International Symposium of the Society of Core Analysts, 2005, SCA2005-01, Toronto, Canada, August 21-25. http://www.jgmaas.com/SCA/2005/SCA2005$\underline{01 . p d f}$

Cao, C.; Huang, T.; Du, F-P. Impact of ionic liquid-type imidazolium surfactant additions on dynamic properties of $\beta$-casein adsorption layer. Food Hydrocolloids, V.36, p. 348-354, 2014. https://doi.org/10.1016/i.foodhyd.2013.08.025

Dong, B.; Zhao, X.; Zheng, L.; Zhang, J.; Li, N.; Inoue, T. Aggregation behavior of long-chain imidazolium ionic liquids in aqueous solution: micellization and characterization of micelle microenvironment. Colloids and Surfaces A: Physicochemical and Engineering Aspects, v.317 (1-3), p. $666-672,2008$.

https://doi.org/10.1016/i.colsurfa.2007.12.001 
Dong, M.; Ma, S.; Liu, Q. Enhanced heavy oil recovery through interfacial instability: A study of chemical flooding for Brintnell heavy oil. Fuel, v.88(6), p. 1049 - 1056, 2009.

https://doi.org/10.1016/i.fuel.2008.11.014

Dyke, K. V. Fundamentals of Petroleum. Austin, 4th edition, 1997, 168p. (in United States). http://cee.utexas.edu/ce/petex/aids/pubs/fundamental s-petroleum/

Hezave, A. Z.; Dorostkar, S.; Ayatollahia, S.; Nabipour, M.; Hemmateenejad, B. Investigating the effect of ionic liquid (1-dodecyl-3methylimidazolium chloride $([\mathrm{C} 12 \mathrm{mim}][\mathrm{Cl}]))$ on the water/oil interfacial tension as a novel surfactant. Colloids and Surfaces A: Physicochemical and Engineering Aspects, v.421, p. 63-71, 2013a. https://doi.org/10.1016/i.colsurfa.2012.12.008

Hezave, A. Z.; Dorostkar, S.; Ayatollahi, S.; Nabipour, M.; Hemmateenejad, B. Dynamic interfacial tension behavior between heavy crude oil and ionic liquid solution (1-dodecyl-3methylimidazolium chloride ([C12mim] $[\mathrm{Cl}]+$ distilled or saline water/heavy crude oil)) as a new surfactant. Journal of Molecular Liquids, v.187, p. $83-89,2013 b$.

https://doi.org/10.1016/i.molliq.2013.05.007

Isaacs, E. E.; Smolek, K. F. Interfacial tension behavior of athabasca bitumen/aqueous surfactant systems. The Canadian Journal of Chemical Engineering, v.61(2), p. $233-240,1983$. https://doi.org/10.1002/cjce.5450610215

José-Alberto, M-H; Jorge, A. Current Knowledge and Potential Applications of lonic Liquids in the Petroleum Industry. In TechOpen book, chapter, 18, 2011. https://doi.org/10.5772/13974

Kumar, B. Effect of Salinity on the Interfacial Tension of Model and Crude Oil Systems. M.Sc. Thesis, University of Calgary, Alberta. 2012. (in Canada). http://hdl.handle.net/11023/195

Lake, L. W. Enhanced oil recovery, Chapter 9Micellar-Polymer flooding, Upper Saddle River, New Jersey, Prentice-Hall, 1989, 437p. (in United States). ISBN 0-13-281601-6
Li, X.; Sun, W.; Wu, G.; He, L.; Li, H.; Sui, H. Ionic liquid enhanced solvent extraction for bitumen recovery from oil sands. Energy \& Fuels. v.25, p. 5224-5231, 2011.

https://doi.org/10.1021/ef2010942

Lima, E. R. A.; de Melo, B. M.; Baptista, L. T.; Paredes, M. L. L. Specific ion effects on the interfacial tension of water/hydrocarbon systems. Brazilian Society of Chemical Engineering, v.30(01), $55-62,2013$.

https://doi.org/10.1590/S0104-66322013000100007

Łuczak, J.; Hupka, J.; Th.ming, J.; Jungnickel, C. Self-organization of imidazolium ionic liquids in aqueous solution. Colloids and Surfaces A: Physicochemical and Engineering Aspects, v.329(3), p. 125-133, 2008.

https://doi.org/10.1016/i.colsurfa.2008.07.012

Modaressi, A.; Sifaoui, H.; Mielcarz, M.; Doma'nska, U.; Rogalski, M. Influence of the molecular structure on the aggregation of imidazolium ionic liquids in aqueous solutions. Colloids and Surfaces A: Physicochemical and Engineering Aspects, v.302(13), p. 181-185, 2007. https://doi.org/10.1016/j.colsurfa.2007.02.020

Mohsenzadeh, A.; Al-Wahaibi, Y.; Jibril, A.; AlHajri, R.; Shuwa, S. The Novel Use of Deep Eutectic Solvents for Enhancing Heavy Oil Recovery. Journal of Petroleum Science and Engineering, v.130, p. 6 $-15,2015 a$.

https://doi.org/10.1016/i.petrol.2015.03.018

Mohsenzadeh, A.; Al-Wahaibi, Y.; Al-Hajri, R.; Jibril, B. Effects of concentration, salinity and injection scenario of ionic liquids analogue in heavy oil recovery enhancement. Journal of Petroleum Science and Engineering, v.133, p. 114-122, 2015b. https://doi.org/10.1016/i.petrol.2015.04.036

Ober, C. A.; Gupta, R. B. pH Control of Ionic Liquids with Carbon Dioxide and Water: 1-Ethyl-3methylimidazolium Acetate. Industrial and Engineering Chemistry Research, v.51(6), p. 25242530, 2012. https://doi.org/10.1021/ie201529d

Painter, P.; Williams, P.; Mannebach, E. Recovery of bitumen from oil or tar sands using ionic liquids. Energy and Fuels, v.24(2), p. 10941098, 2010. https://doi.org/10.1021/ef9009586 
Pereira, J. F. B.; Costa, R. ; Foios, N.; Coutinho, J. A. P. Ionic liquid enhanced oil recovery in sandpack columns. Fuel, v.134, p. 196-200, 2014. https://doi.org/10.1016/i.fuel.2014.05.055

Schramm, L. L. Surfactants: Fundamentals and Applications in the Petroleum Industry. Cambridge, Cambridge University Press, 2000, 5p. (in United Kingdom).

Shaddel, S.; Tabatabae-Nejad, S. A.; Fathi, S. J. Low Salinity Water Flooding: Evaluating the Effect of Salinity on Oil and Water Relative Permeability, Wettability and Oil Recovery. Special Topics and Reviews in Porous Media-An International Journal, v.4(2), p. 133-143, 2014. https://doi.org/10.1615/SpecialTopicsRevPorousMedia. $\underline{\mathrm{v} 5 . \mathrm{i} 2.40}$

Thakkar, K.; Bharatiya, B.; Shah, D. O.; Ray, D.; Aswal, V. K.; Bahadur, P. Interaction of ionic liquid type cationic surfactants with triton $X-100$ nonionic micelles. Colloids and Surfaces A: Physicochemical and Engineering Aspects, v.484, p. 547-557, 2015. https://doi.org/10.1016/i.colsurfa.2015.08.039
Wang, H.; Feng, Q.; Wang, J.; Zhang, H. Salt effect on the aggregation behavior of 1-decyl-3methylimidazolium bromide in aqueous solutions. Journal of Physical Chemistry B, v.114(3), p. 13801387, 2010. https://doi.org/10.1021/ip910903s

Xu, J.; Zhang, Y.; Chen, H.; Wang, P.; Xie, Z.; Yao, Y.; Yan, Y.; Zhang, J. Effect of surfactant headgroups on the oil/water interface: An interfacial tension measurement and simulation study. Journal of Molecular Structure, v.1052, p. 50-56, 2013.

https://doi.org/10.1016/j.molstruc.2013.07.049

Zhao, H.; Xia, S.; Ma, P. Use of ionic liquids as 'green' solvents for extractions. Journal of Chemical Technology and Biotechnology, v.80(10), p. 1089-1096, 2005.

https://doi.org/10.1002/jctb.1333 